International Journal of Advanced Technology in Mechanical, Mechatronics and Materials

(IJATEC)

Vol. 02, No. 1 (2021) 46-54

Institute for Research on Innovation and Industrial System (IRIS)

\title{
Synchronization of Catch Fish Data in Fisheries e-Logbook with a Vessel Monitoring System
}

\author{
Abdi Wahab $^{\mathrm{a}^{*}}$, Bayu Waseso ${ }^{\mathrm{a}}$, Hadi Pranoto ${ }^{\mathrm{b}}$ \\ anformation System, Faculty of Computer Science, Universitas Mercu Buana, Jakarta, Indonesia \\ ${ }^{b}$ Department of Mechanical Engineering, Faculty of Engineering, Universitas Mercu Buana, Jakarta, Indonesia
}

\begin{abstract}
Indonesia as an archipelago country has many residents whose livelihoods is fishermen. Traditional fishermen who are scattered in various provinces need a tool that can help to record fish catch data after they sail. This study aims to propose a method for synchronizing fish catch data between e-logbook and a fishing vessel monitoring system. The Unix timestamp reference was used to help synchronize fish catch data with the position in the monitoring system, and it was expected to run well. The results of this study are fisheries e-logbooks for Android devices equipped with data synchronization features. In the future, it would be better if a tool was made to help transmit data from the middle of the sea for traditional fishermen.
\end{abstract}

Keywords: fisheries e-logbook; vessel monitoring system; unix timestamp

DOI: $10.37869 /$ ijatec.v2i1.43

Received 13 March 2021; Accepted 27 March 2021; Available online 19 April 2021

(C) The Authors. Published by IRIS. This is an open access article under the CC BY-NC-SA license cC) (i) (3)

\section{Introduction}

Indonesia, which is geographically an archipelagic country, has sea that is wider than land, the population depends on the sea for their livelihoods. Some Indonesian residents work as fishermen, salt farmers, sea sand miners, sea sand gold miners, and so on. Indonesia's abundant marine wealth is a blessing for residents who live on the coast.

Especially for fishermen, who sail in the sea to catch fish, there are two categories based on the boats used by the fishermen. First, large fishermen who have vessels of more than 30 GT (Gross Tonnage), and second are small fishermen who have vessels under 30 GT. Equipment owned by large fishermen, both for fishing and supporting equipment, is very complete. Meanwhile, small fishermen are very limited. Large fishermen based on statutory regulations in Indonesia, must be equipped with a fishing boat monitoring system, one of which is to record data on the fish catch they have caught. Meanwhile, small fishermen are not equipped with this monitoring system, so their catch data cannot be known with certainty.

Basically, the recording of catch data is required by the Office of Marine Affairs and Fisheries (DKP) in each province, one of which is to determine the types and quantities of fish caught by the province. On average, small fishermen have problems recording this catch data due to the lack of tools that can help them record. In practice in the field, they were provided with a paper to record the catch by DKP officers, but the paper was more damaged due to tearing or missing.

Based on the above problems, it is necessary to make a record that is not easily lost to help fishermen to record their catch. And to assist in sending data with a fishing boat monitoring system, it is also necessary to make a way to synchronize catch data with a fishing boat monitoring system that has been built in research [1] so that the catch data and the position of fishermen to catch fish can be determined. 
In this study, a fisheries e-logbook will be developed that can be used to record catch data, and a method will also be proposed to help synchronize fish catch data with the fishing vessel monitoring system that was created in previous studies. This research is the development of research conducted by Waseso, B. [1] regarding the design of a fishing Vessel Monitoring System (VMS) for vessels under 30 GT. The method used for designing the SPKP in Waseso's research used the incremental method.

Several studies related to this research include research conducted by Chang, S.K [2]. In Chang's research, a Vessel Monitoring System (VMS) was developed as a medium for regulating sustainable fisheries in Taiwan, and also discussed some of the advantages that Taiwan has in using VMS.

Further research related to this research is the research of Hadhi Nugroho, Agus Sufyan, and Rudhy Akhwady [3]. In his research entitled Integration of Fishing Logbook Electronic System (ELPI) with fishery ship or Vessel Monitoring System (VMS) for sustainable fisheries development, a VMS was created which was integrated with a special tool to record fish catches. A device designed to use a GPRS signal to communicate with a server that has been provided in the data center. The tool is made specifically for ships above or equal to $30 \mathrm{GT}$, because it requires electrical power for operation. In the research that will be conducted by the author, the system developed is more for small fishermen or fishermen who have boats under 30 GT. The devices used are devices that can be easily found at shopping centers.

The next research is a research conducted by Zach McCormick, and Douglas C. Schmidt [4] with the title data synchronization pattern in mobile application Design. In their research, a pattern was constructed for data synchronization specifically for mobile applications.

Another research about VMS was done by Ferreira and Martins [5], developing intelligent VMS system for deciding which data must be transmitted via satellite. In articles [6] and [7] discuss about regulation for Vessel Monitoring System. In article [8], discuss about e-logbook based on Android, and article [9] discuss about e-logbook implementation and industry perception. In article [10], elogbook was used in medical for recoding patient record. Related to Unix Timestamp in article [11] comparing it with UTC and date time, and for fisheries area, articles in [12], [13] are research related to it.

\subsection{Logbook}

A logbook or notebook is a note or journal that records certain activities, such as operational activities, management, navigation, etc., or other records as a temporary set of data before the data in the logbook is further processed. Logbook on reasonable use is carried out every day, so that the data can be stored properly.

\section{2 e-Logbook}

E-logbook is a digital version of the logbook or in software form. Several other studies have made elogbooks in various versions. In this study, the e-logbook was developed specifically for the Android platform, both smartphones and tablets.

This e-logbook was developed for fisheries, and is intended for fishermen who have a time below $30 \mathrm{GT}$. Some of the features that will be developed in this e-logbook include recording data on catches, sailing registration by fishermen to the VMS server. For the second feature, it is intended that the ship owner knows which fishermen are going to sail and knows when they will return.

\subsection{Vessel Monitoring System}

The fishing boat monitoring system used in this study is based on research conducted in [1]. The VMS built is intended for small fishermen or those who have boats under 30 GT. These traditional fishermen are not legally required to use VMS owned by the government, but the need for a monitoring system and also with security considerations, so boat owners who usually supervise fishermen need a fishing boat monitoring system.

The concept of the existing VMS, which is owned by the Indonesian government, can be seen in Figure 1. This concept requires a device that can communicate directly via satellite and can also transmit the position of the fishing boat on the spot. This concept is only intended for fishermen who own boats starting from 30 GT. Licensing using this system is carried out at the central Ministry of Marine Affairs and Fisheries in Jakarta. 


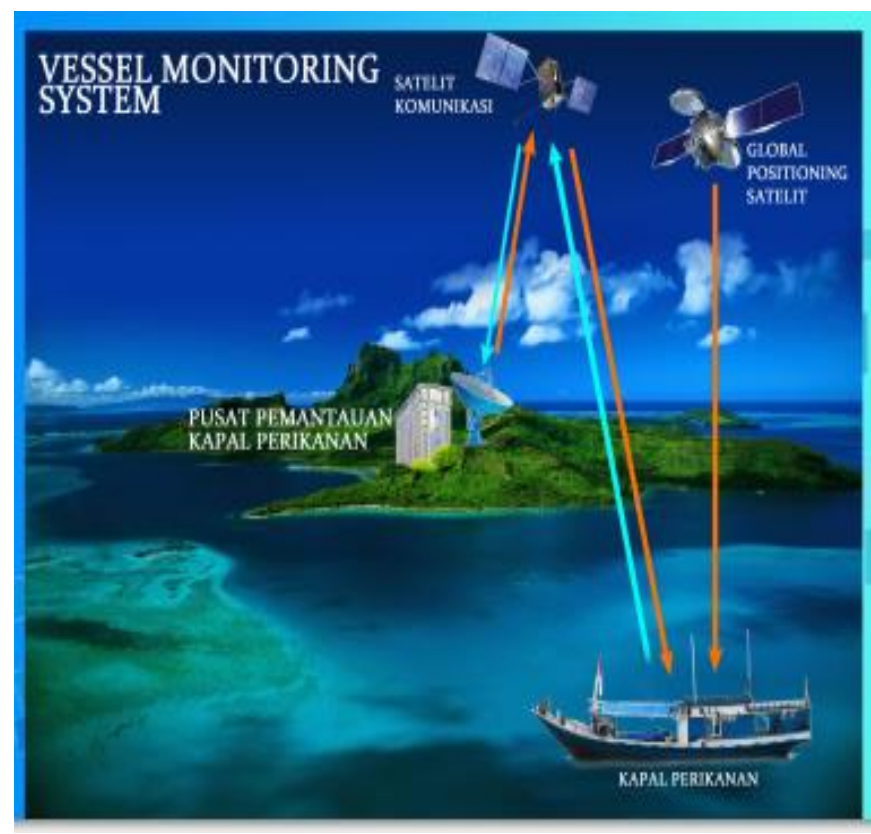

Figure 1. VMS concept in Indonesia [5]

\subsection{Unix Timestamp}

The Unix timestamp is a pattern of writing times in seconds starting from January 1, 1970. UTC. This time system records the elapsed seconds starting from the specified start date. This causes the use of the Unix timestamp or commonly referred to as the Unix epoch or also the POSIX time, which has the same value in various parts of the world, not limited by the time zone in each country. This standardization allows it to be used as a time reference in various systems without the need for a time zone which sometimes confuses the system.

\section{Research Methodology}

The research method that will be developed in this study in outline follows the flow in Figure 2 . The stages for the research method carried out by the author in this study consist of developing a VMS and fisheries e-logbook, then making an algorithm for synchronizing catch data with VMS, followed by the implementation of synchronization algorithms in the e-logbook and VMS, and finally testing the synchronization of data captured from the e-logbook to VMS. These stages will be explained further in the section below.

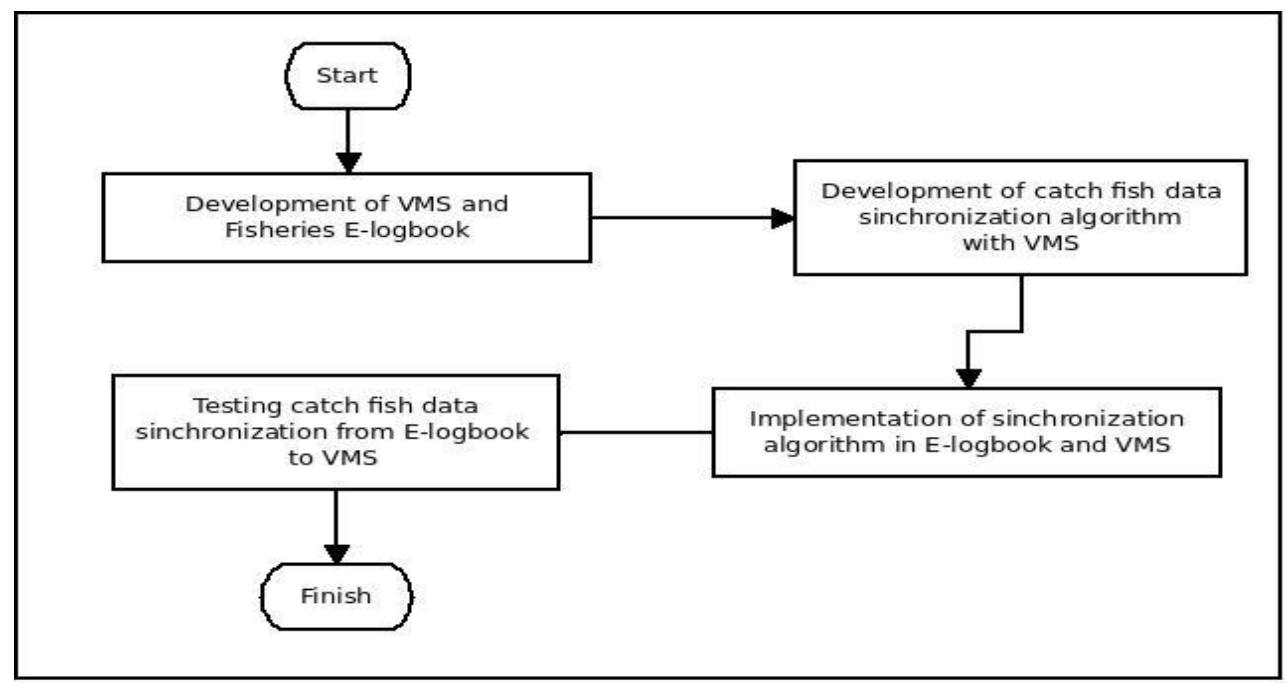

Figure 2. Research Methodology of this research 


\subsection{Development of VMS and Fisheries e-logbook}

The stages of developing VMS and fisheries e-Logbooks are the stages of developing web-based software for VMS, and mobile-based for smart phones for e-Logbooks. In use, VMS will also act as the server of the e-Logbook, so that it will create a concept of a client-server application between VMS and e-Logbook.

VMS development stages use the iterative method, with the first step taken is analyzing the system to be built. To get the expected analysis, the researcher conducted a direct visit to the field to see the sailing and fishing process. A review of the process of sailing and catching fish is carried out at the Labuan Fishing Spot, East Lombok. The results of this analysis will be used as input for the system to be developed.

The Use Case diagram for VMS based on the results of the analysis can be seen in Figure 3. In the Use Case diagram in Figure 3, VMS only acts as an administrative system and a monitoring system. The role of boat owner is added to this system, because small fishing vessels are owned by the ship owner, or small boat entrepreneurs for fishermen, not owned by the fishermen themselves.

While the stages for e-Logbook development use the prototyping software development method. This method was taken, because previously there was no e-Logbook concept in fisheries, especially in the Labuan area, East Lombok. Therefore, the prototyping method is used to facilitate the development of this e-Logbook.

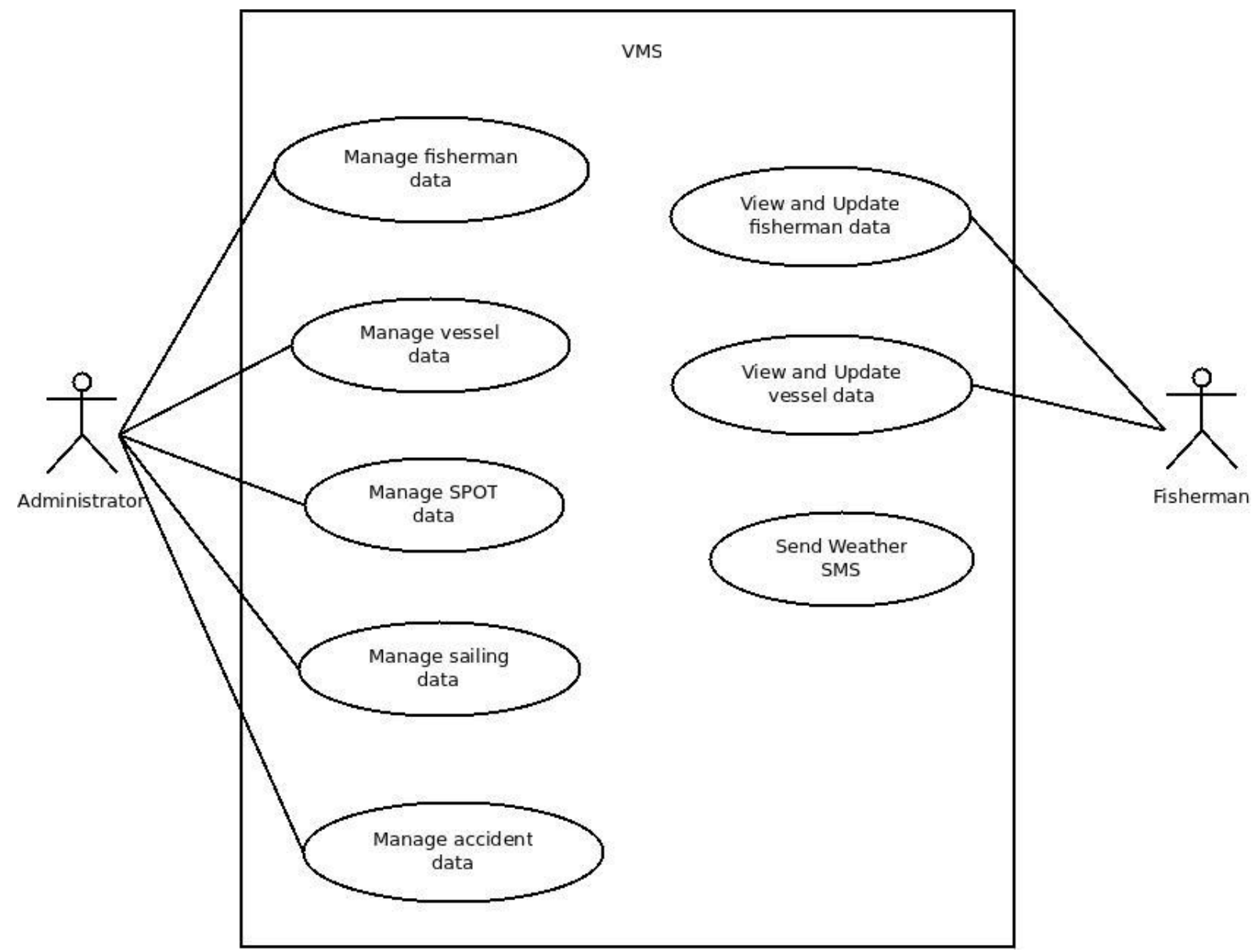

Figure 3. The proposed VMS Use Case [1]

E-Logbook when illustrated with a use case diagram can be seen in Figure 4. The function of the e-Logbook in the Use Case diagram in Figure 4 is used as a client system of VMS. Its duties include helping to register fishermen to sail and to record the fishermen's catch. The e-logbook is also equipped with a data synchronization feature of fish catches from client to server. 


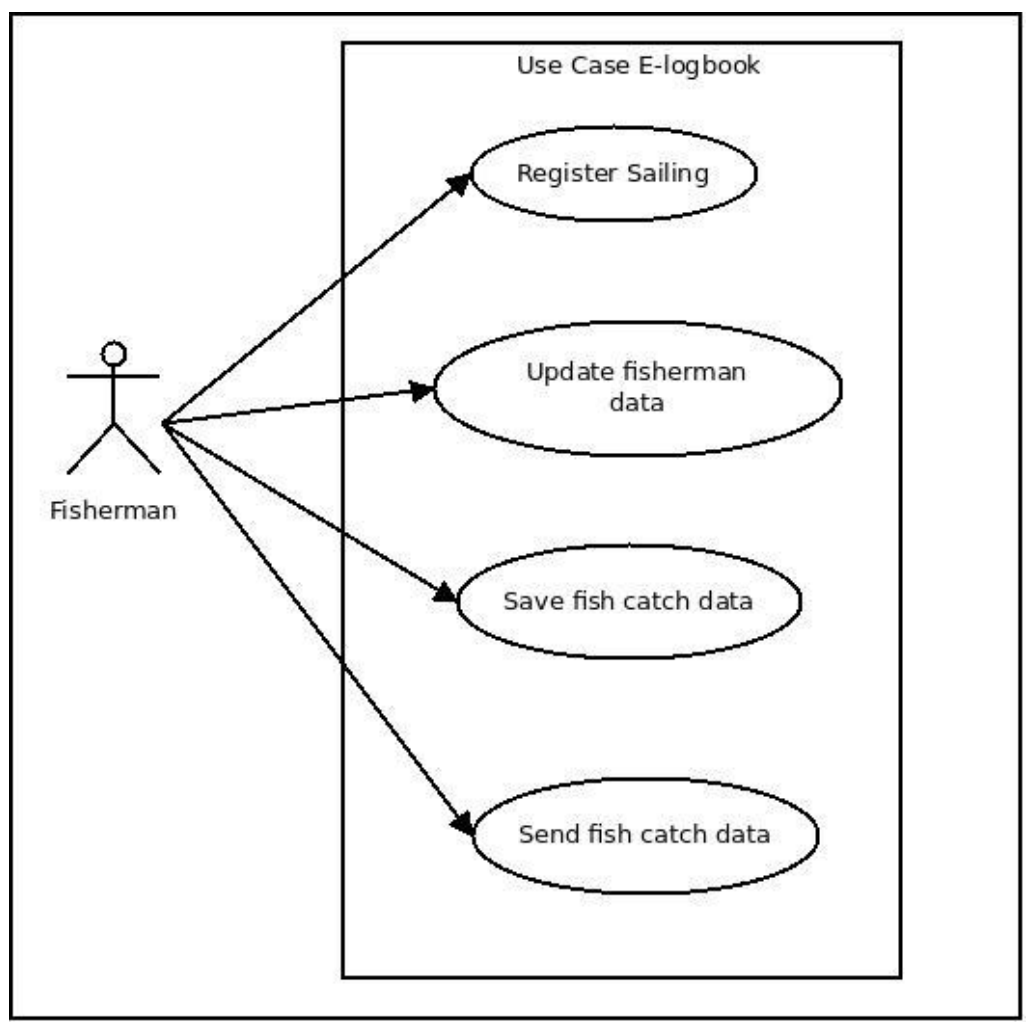

Figure 4. Use case for e-logbook

The VMS system which is made for small fishermen is also equipped with a GPS tracker which helps in providing the position of the fishing boat when sailing fishing in the sea. The working principle of the VMS proposed in this study is depicted in Figure 5.

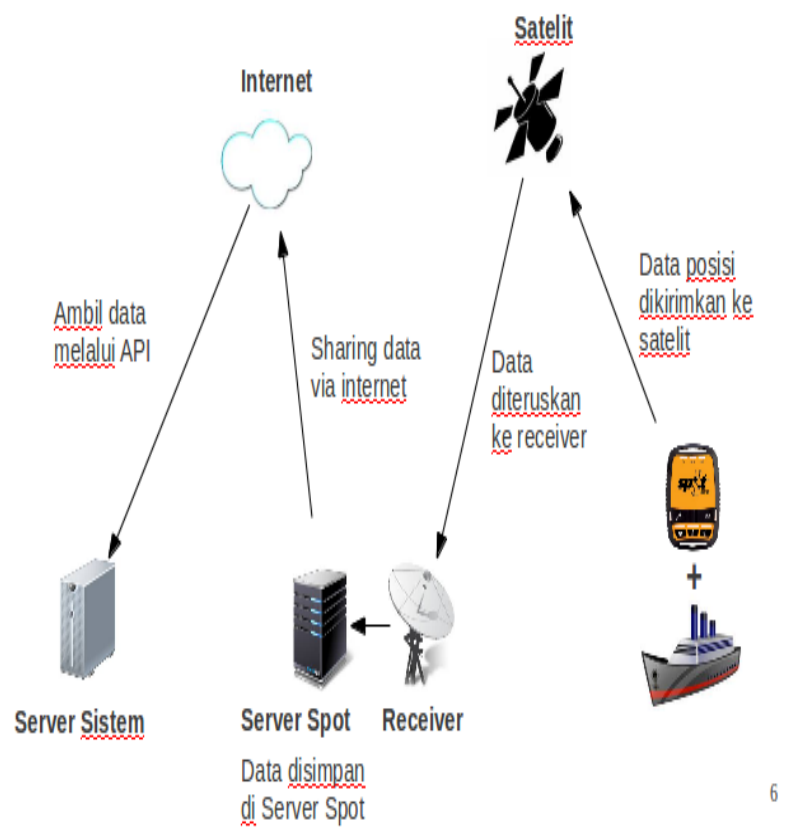

Figure 5. Proposed VMS [4]

The GPS used in Figure 5 is the GPS Spot which is the standard GPS used for tracking. Its use uses a battery and can be recharged for the battery. This GPS Spot will provide the fisherman's position which is temporarily stored on the SPOT server, and through the Application Programming Interface (API) the position can be accessed to be moved to the VMS server.

Especially for the synchronization feature, the captured data will be sent to the server from temporary storage by the e-Logbook application. Therefore, this feature requires a special algorithm 
that helps the captured data be linked to the GPS position data that has been taken from the Spot server.

\subsection{Catch Data Synchronization Algorithm}

This stage will develop an algorithm to synchronize the catch data with the GPS data that has been taken from the Spot server. Synchronization is required so that the catch data at one fishing point can be connected with the incoming GPS data from the Spot server, so that it can be presented properly on the map in the VMS.

The results of the analysis carried out to synchronize are using a Unix timestamp parameter that is in the Spot server data. Comparing the Unix timestamp in the captured data with the GPS data from the Spot server, synchronization can be done. The algorithm that is being developed to synchronize is as follows:

1. Read Unix time data on catch data

2. Check if there is a Unix time on the GPS data equal to or more or less close to the Unix time that has been read from the captured data?

3. If there is, then connect the captured data with the GPS data on the VMS server.

\subsection{Implementation of synchronization algorithms on e-Logbook and VMS}

After the synchronization algorithm has been developed, the next step is to implement the algorithm into the e-Logbook and also the VMS. The implementation of the synchronization algorithm will only be implemented on VMS, while the e-Logbook will trigger the algorithm, because the process of synchronizing fish catch data and GPS data from the Spot server that can start is the e-Logbook.

The synchronization algorithm implementation will be added to the API in VMS. A special API in VMS will be created to handle this data synchronization. E-Logbook can easily access the API to start synchronizing fish catch data into the VMS server. Each fish catch data is sent to the VMS server via this special API, and will run a synchronization algorithm, so that the fish catch data will be linked to the GPS data.

\subsection{Testing e-Logbook and synchronization algorithms}

Testing of implementation results will be discussed in section IV, Results and Discussion. Testing the e-logbook will use the black box testing method. Meanwhile, the implementation of the synchronization algorithm uses direct field testing.

\section{Results and Discussion}

The results of implementing the synchronization algorithm will be discussed in this chapter. The first step to take is to test the e-logbook using the black box method. Then the second test is carried out to test the synchronization algorithm from the implementation results on the VMS server. Testing at this stage is done by simulating sailing and catching fish using an e-Logbook, and a GPS Spot device that has been connected to the VMS. The test was carried out in the Labuan area, East Lombok, to be precise in the Bali Strait, which is the strait that separates the island of Lombok from the island of Sumba. This chapter will also display several views of the e-logbook application that has been built and integrated with the Fishing Vessel Monitoring System.

\subsection{Testing of e-Logbook with black box method}

Testing the e-logbook with the black box method for the e-logbook concept went well, and in accordance with the expected scenario.

\subsection{Display of results from the e-logbook that has been developed}

In this section, some views of the e-logbook application that have been developed in this study will be displayed. Some of these views can be seen in Figure 6 . 


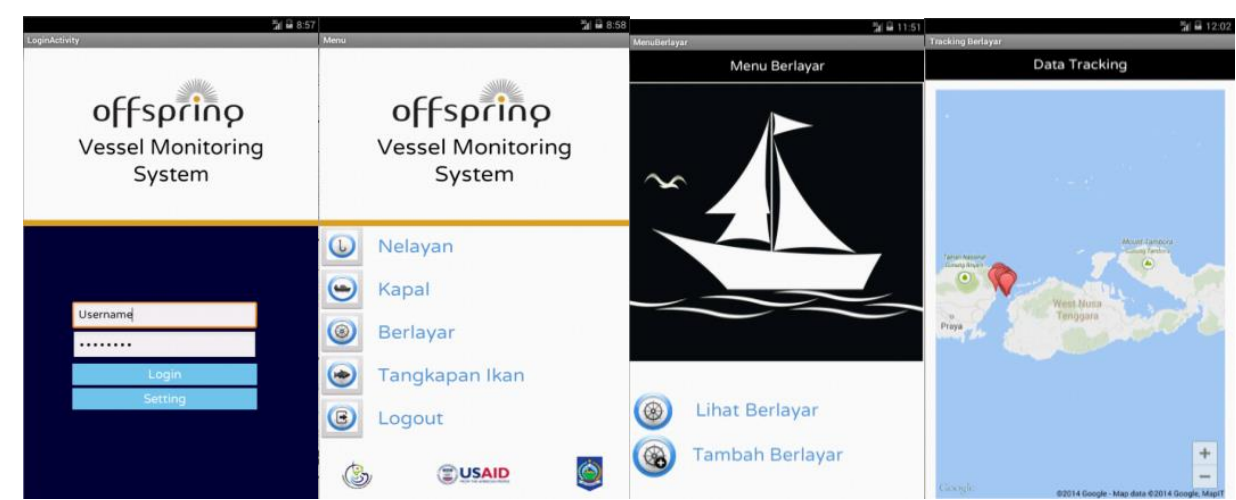

Figure 6. Some Display of e-Logbook Application

In Figure 6, the e-logbook display is made easy to use by fishermen who will become users of this application. The display is simple and has a large icon so fishermen can quickly understand the elogbook application.

\subsection{Testing of Synchronization Algorithm}

Synchronization algorithm testing using the Unix timestamp reference is carried out directly in the field. Testing is done by making a fishing simulation, and then the e-logbook application temporarily stores the data that has been entered into the e-logbook. When the fishermen have arrived at the dock, where there is an internet connection, the e-logbook will synchronize to the VMS server.

Figure 7 shows the catch data that is temporarily stored in the e-logbook application. This data storage is carried out in the middle of the sea, because there is no internet connection in the middle of the sea, so the data must be stored in an e-logbook first. Figure 8 illustrates the catch data synchronized with VMS data. The place to store fish catch data in the middle of the sea will be combined with the position data from the GPS that has been entered into the VMS server. Thus, the approximate position of the fishing ground can be determined and linked to GPS data.

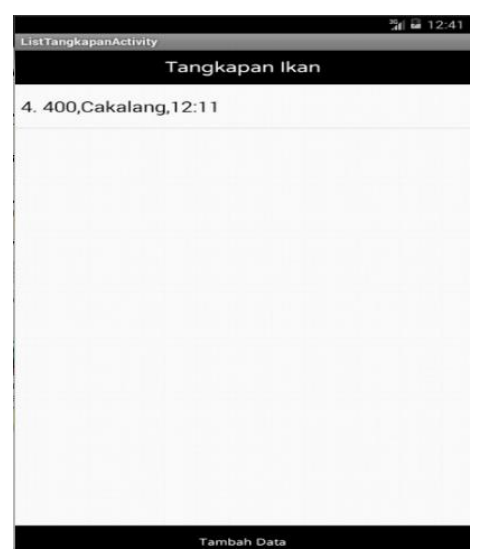

Figure 7. Catch data stored in e-logbook

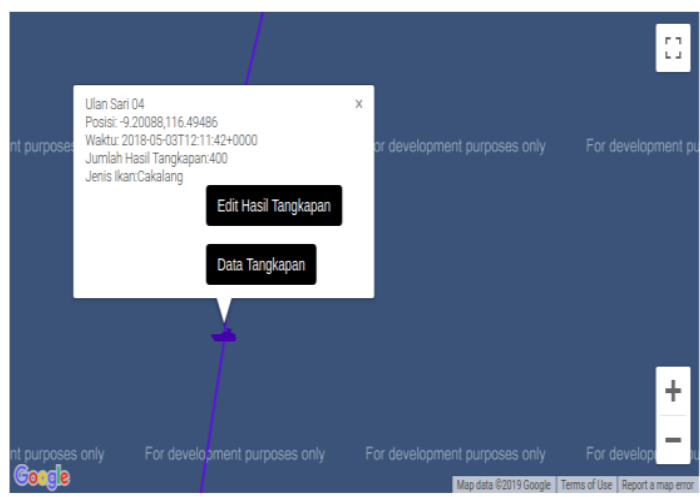

Figure 8. Catch data synchronized with VMS 
Testing using the black box method has also been carried out in the development of this e-logbook application. The results obtained by testing using the black box method are that the application runs according to the desired scenario.

\subsection{Analysis of test results}

After testing both for testing the system being built and also testing the catch data synchronization algorithm, there are several findings that can be used as a discussion in this section. One of the findings by researchers during data synchronization testing was the similarity in time between the smart phones used to run the e-logbook application and the VMS server. This is necessary so that the prediction of fishing grounds becomes more precise. So that researchers need to make a work step for the operation of this system, and the time equalization between the smart phone and the VMS server will be included in this work step.

Another thing that is obtained when testing is the power of the smart phone that will be sailed. If you look at the activities of fishermen who can sail for up to 1-2 weeks in the middle of the sea, the smartphone that will be carried will not be enough. However, this problem can be overcome by having a portable power source (Generator Set) which is currently owned by fishermen with boats under $30 \mathrm{GT}$.

\section{Conclusions}

This study proposes an algorithm for synchronizing fish catch data between E-logbook and VMS (Vessel Monitoring System). Based on the test results, the fish catch data synchronization algorithm runs well with the time conditions between the smart phones with the E-logbook application and the same VMS server. This condition will make the position of the fish catch more precise in accordance with the position of entering fish catch data when fishing in the middle of the sea. In the future, it will be better, if a tool is developed that can help smart phones transmit data from the middle of the sea, so that data can be sent directly without having to be stored on a smartphone first.

\section{References}

[1] S. K. Chang, "Application of Vessel Monitoring System to Advance Sustainable Fisheries Management - Benefits Received in Taiwan," Marine Policy 35(2): 116-121, 2011.

[2] H. Nugroho, A. Sufyan and R. Akhwady, "Integrasi Sistem Elektronik Log Book Penangkapan Ikan (ELPI) dengan Sistem Pemantau Kapal Perikanan (VMS) Untuk Pembangunan Perikanan Berkelanjutan," Jurnal Kelautan Nasional, vol. 8, no. 3, Desember 2013.

[3] Z. Mccormick and D. C. Schmidth, "Data Synchronization Patterns In Mobile Application Design," Proceedings of the Pattern Languages of Programs (PLoP), Tucson, Arizona, 2012.

[4] B. Waseso, A. Wahab, "Perancangan Sistem Pemantau Kapal Perikanan (SPKP) Untuk Kapal di Bawah 30 GT Dengan Metode Incremental," Incomtech, Jurnal Penelitian Tehnologi Informatika dan Komunikasi, vol. 7, no. 1, Juni 2018.

[5] J.C. Ferreira, and A.L. Martins, “Edge Computing Approach for Vessel Monitoring System," Energies $2019,12,3087$.

[6] A. Soemarmi, E. Indarti, Pujiyono, L.T.A.L Wardhani, A. Diamantina, A. Ristyawati, "The Use of Vessel Monitoring System as Fishery Ship Obligations in Indonesia," AACL Bioflux, Volume 13, Issue 3, 2020.

[7] J.T. Watson, A.C. Haynie, P.J. Sullivan, L. Perruso, S. O’Farrell, J.N. Sanchirico, F.J. Mueter, “Vessel Monitoring System (VMS) Reveal an Increase in Fishing Efficiency Following Regulatory Changes in a Demersal Longline Fishery," Fisheries Research Vol. 207, 85-94, 2018.

[8] J.V. Joshua, O.D. Alao, E. Ogbudje, O.K. Ogundipe, "ELogbook: An Android-Based Logbook System," IUP Journal of Computer Sciences, Vol 13, Iss. 3, July 2019.

[9] M. Change, "eLogbook Implementation: Benefits, Industry Perception, and Opportunities," Article of USAID Ocean and Fisheries Partnership, Retrieved By 10 December 2020 in: http://repository.seafdec.or.th/bitstream/handle/20.500.12067/1164/USAID-

Oceans eLogbooks-Case-Study-202502-final.pdf?sequence $=1$ 
[10] N.M.M.N.M. Rosdy, M.H. Mohammadiah, M.A.A.M. Tajuddin, A.A. Rusly, A.M. Ishak, A.F.M. Fadzil, M.F. Jamaludin, "Development of Student's Clinical Training Record and Assessment Application via Patient Records," Advanced Science Letters, Vol. 24, 303-306, 2018.

[11] E. Hauser, "UNIX Time, UTC, and datetime: Jussivity, prolepsis, and incorrigibility in modern timekeeping," Proceedings of The Association for Information Science and Technology, Volume 55, Issue 1, 2018.

[12] D. Fitrianah, H. Fahmi, A.N. Hidayanto, A.M. Arymurthy, "A Data Mining Based Approach for Determining the Potential Fishing Zones," International Journal of Information and Education Technology, Vol. 6, No. 3, March 2016.

[13] Suraya, P.B. Sulistyo, "Sosialisasi Identifikasi Peluang Usaha Kelautan dan Perikanan di Pesisir Pantai Sawarna - Lebak Banten," Jurnal Abdi MOESTOPO, Vol. 02, No. 01, 2019. 